\title{
Social Media and Journalism: 10 Years Later, Untangling Key Assumptions
}

\author{
Seth C. Lewis \\ University of Oregon \\ sclewis@uoregon.edu
}

\author{
Logan Molyneux \\ Temple University \\ logan@temple.edu
}

\begin{abstract}
Amid a broader reckoning about the role of social media in public life, this article argues that the same scrutiny can be applied to the journalism studies field and its approaches to examining social media. A decade later, what hath such research wrought? We need a more particular accounting of the assumptions, biases, and blind spots that have crept into this line of research as well as the study of mediated conversations broadly. Our purpose is to provoke reflection and chart a path for future research by critiquing themes of what has come before. In particular, we seek to untangle three faulty assumptions-often implicit but no less influential-that have been overlooked in the rapid take-up of social media as a key phenomenon for journalism studies particularly and digital media studies generally: (1) that social media would be a net positive; (2) that social media reflects reality; and (3) that social media matters over and above other factors.
\end{abstract}

\section{Introduction}

In 2015, when the first author visited a U.S. metropolitan newspaper in the throes of trying to reinvent itself for the digital era, a management ultimatum had recently been delivered to the few reluctant late-adopters there: Be an active contributor on social media, or else. The message went something like this: If you're not on Twitter, get an account already-and make sure you have at least a few hundred followers by the end of the year. We'll be tracking your activity. ${ }^{1}$ The intensity of the message matched the urgency that the newspaper's managers feltan urgency about meeting audiences where they were (increasingly on social platforms outside the newspaper's control) and thereby steering those audiences back to the newspaper's own proprietary platforms (its website and apps). The hope was that social media, once a curiosity beginning with MySpace in the mid-2000s and now suddenly the dominant means of public conversation, might be just the thing to save news organizations - to revitalize, and hopefully monetize, audience attention in a world awash in attractive alternatives to news. To be active on Twitter and Facebook, as well as Snapchat, Instagram, and the rest, was seen by many news managers as an obvious and necessary step in journalism's digital-first transformation.

In many cases, journalists actually were ahead of their bosses as early and eager adopters of social media, embracing the opportunity to develop a personal brand, follow and converse with fellow journalists, seek new sources and ideas, and enjoy a metric-based manifestation that people indeed liked and shared their work. For many journalists, being on social media also meant being exposed to unruly publics and their criticisms, and feeling obligated to manage yet another platform around the clock. But the general story of social media and journalism, as told through public discourse and by now scores of academic studies published in the past decade, is one of journalists readily adopting and navigating an intriguing new space, overall adapting it to meet their needs and reaffirm their journalistic authority. More to the point, the collective hope for social media and journalism over the past decade, as painted especially in the trade press but also in the academic literature, has been one of implicit positivity: that, on balance, social media would be a net benefit for individual journalists, for journalism as an institution, and for society as a whole.

How things have changed. Social media, once heralded for its role in democratic uprisings around the world and seen as a critical point of passage for activism in the digital age [80], is now being re-evaluated for its social impact, amid broader questions about data privacy, hacking, and government surveillance, as well as doxxing, harassment, and hate speech online [35][82]. Particularly in the United States but elsewhere as well, the public narrative about social media changed dramatically after the 2016 election of President Donald J. Trump, which brought to the fore concerns about widespread malfeasance on social media-from "fake news," propaganda, and coordinated disinformation to bot-based media manipulation and alt-right trolling and misogyny [50]. Summing up the increasingly sour mood by the end of 2017, The Economist [79] was led to wonder, "Do social media threaten democracy? Facebook, Google and Twitter

\footnotetext{
${ }^{1}$ Personal communication, July 9, 2015; newspaper name withheld by agreement.
} 
were supposed to save politics as good information drove out prejudice and falsehood. Something has gone very wrong."

Perhaps the same could be said about the intersection of social media and journalism, particularly as situated within the broader study of mediated conversations and their implications for social life. At one level, there is the institutional threat of social media, as Google and Facebook vacuum up digital advertising revenue at an unprecedented rate, leading some observers to conclude that " $[\mathrm{t}]$ he influence of social media platforms and technology companies is having a greater effect on American journalism than even the shift from print to digital"; this because of the widespread takeover of traditional publishing roles by platforms that "have evolved beyond their role as distribution channels, and now control what audiences see and who gets paid for their attention, and even what format and type of journalism flourishes" [7]. But where publishers once embraced platforms as a new and possibly superior distribution method, many are now seeing referral traffic decline and some are even quitting Facebook, saying, "It's been good for Facebook, but it hasn't been good for us" (quoted in [64]). At another level is the lived experience of journalists on social media. While journalists have always faced criticism for their work, and while violence and intimidation against the press can be far more acute in repressive regimes [17], there is growing evidence that online culture generally and social media interactions specifically are contributing to a growing level of hostility and harassment for journalists in the West [74], particularly at a time when leading politicians in supposedly "safe" countries actively question the legitimacy of journalists and their work [9].

This moment of reckoning, both about social media and public life as well as social media and journalism practice, can be extended to include academic inquiries as well: A decade later, what hath research wrought? In the broad study of journalism and its digital transformation, few topics have captivated researchers in the past 10 years or so quite like social media-its use by journalists, its interstitial role between journalists and audiences, its ambient, ephemeral, and spreadable nature, and so much more. Now, after hundreds of studies on journalism and social media, we need a more particular accounting of the assumptions, biases, and blind spots that have crept into this line of research. To be sure, the research thus far has been far-reaching and richly informative, and a comprehensive review of such literature is beyond the scope of this paper (for overviews, see, e.g., [39][40]). Rather, our purpose is to offer a provocation for future research by critiquing themes of what has come before. In particular, our goal is to explain and untangle three key assumptions that have been overlooked in the rapid takeup of social media as a key phenomenon for journalism studies and the wider study of digitally mediated conversations: (1) that social media would be a net positive; (2) that social media reflects reality; and (3) that social media matters over and above other factors.

\section{Background}

First, a brief word about how we are defining terms and contexts. The term "social media" has a history longer than the one we investigate here [33]. In its broadest sense, it could be applied to any medium that enhances interpersonal communication, from $\mathrm{CB}$ radios to Google Hangouts. In the early 2000s, blogs and then specific sites such as Friendster and MySpace were early social media ventures that shaped expectations for a participatory Web. But we classify "social media" the way it is now used colloquially, which is to refer to social networking sites, apps, and platforms. These, as defined by [11] allow individuals to create a public profile, build a network of connections, and "view and traverse" these connections and profiles (for elaboration, see [18]). By far the most popular and powerful of these, and indeed the standard by which all other social media are measured, is Facebook. Thus, social media as we know them took hold in 2006, the year when Facebook and Twitter, two of the most widely used social media platforms today, both became available to the general public.

At that time, the relationship of social media to journalism was not immediately clear; researchers and industry observers were captivated by the potential of blogging, and the term "social media" wasn't common parlance. When Facebook launched its algorithmically generated News Feed in 2006, becoming a dominant distributor of news was never the company's desired goal [15]. But just a few years later, in the midst of a global recession, newsrooms everywhere - but particularly in the United States, where the prevailing news business models were heavily reliant on advertising revenue-began shrinking as advertisers and consumers cut their spending [29]. The question quickly became what could "save" journalism, and the immediate and expedient answer was social media (for some context, consider [5]). These platforms were experiencing exponential growth (Twitter, for instance, ballooned from a few million active users in 2008 to more than 100 million in 2011), and newsmakers rushed to follow audiences there [63]. The thinking was that this new method of communication would enhance news distribution and enable stronger connections between journalists and their audiences [55]. Indeed, such hopes were the culmination of burgeoning expectations in the 2000 s, on the part of industry professionals and academics alike, that citizen engagement in news-making would rejuvenate journalism and democracy. Those expectations, as [68] explains in his article on "dark participation" in this special issue, have since proven to be wildly mistaken: "Media managers' economic fantasies of a willing, free workforce were equally misguided as the rather naïve academic notions of a revitalized journalism in direct debate with its active users; both sacrificed empirical 
realism for fantasies that were driven by their own goals and hopes resulting in either a greedy or an idealistic projection."

Now, a decade after social media was seen in some quarters as journalism's savior as well as a vital catalyst for connection and social change broadly, it is being decried as a cesspool of misinformation and fake news (e.g., [32]). This rise and fall of social media is but one example of a tendency in journalism's trade discourse to prop up a succession of technologies as the means of saving journalism (or at least markedly improving it). Over the years, multiple innovations have emerged as the thing that would rescue journalism, only to be replaced by the next idea: multimedia storytelling, customization and personalization, online video, mobile devices, mobile apps, paywalls, and now virtual and augmented reality. Each has come with overinflated expectations that were eventually tempered by a more modest appraisal [23]. Social media, however, has proven particularly persistent among journalists. Nearly all of them use social media in their work, and many say it is essential [85].

In parallel, researchers studying journalism and social media also jumped in with both feet in 2008, and have not lost interest. According to Google Scholar, the number of new research works mentioning social media and journalism to some degree nearly doubled each year from 2008 (993 articles) to 2011 (5,440 articles). The number of new articles, chapters, and books peaked at 16,600 in 2016 (see Figure 1).

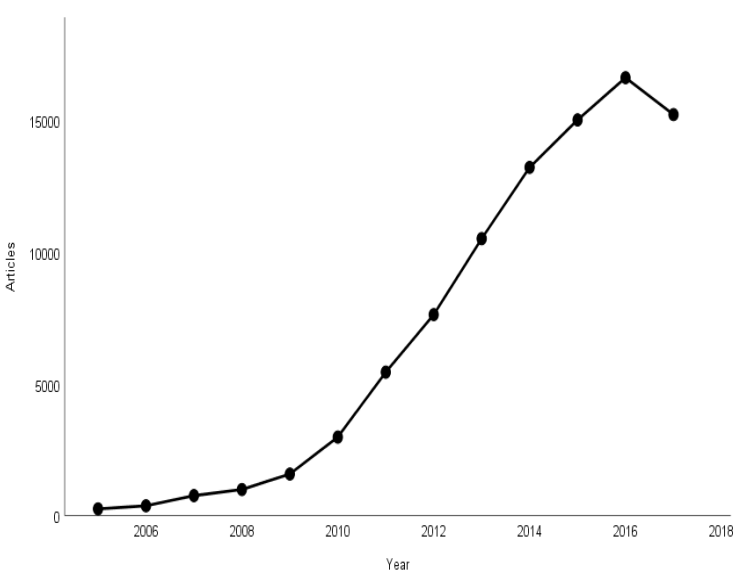

Figure 1. Number of search results for the query "“social media' journalism" in Google Scholar, accounting for new articles published in each of the years 2005 through 2017.

This body of research on journalism and social media has multiple homes, including connections to sociology, behavioral economics, and psychology, as well as contemporary pursuits in political communication especially as well as media and communication studies broadly. Our assessment focuses on work within journalism studies, a field defined not merely by its topical focus on news but particularly by its exploration of the many contexts and processes through which journalism emerges [16]. This narrower focus on journalism studies has two reasons. First, journalism studies has become recognizable as its own field, distinct from others adjacent to it, much more recently than those mentioned above (e.g., the field's two oldest journals, Journalism and Journalism Studies, were both founded in 2000). It is therefore incumbent on those working in this field to continue articulating and clarifying its basis for research, including especially the assumptions that underlie this work. Second, the field's unique identity has been profoundly influenced by the study of journalism and social media, partially because journalism studies has grown up in the social media era. Thus, while other fields also study social media and journalism, the assumptions described here are of particular relevance to journalism studies and have not been examined explicitly within that field. This is particularly true of research that examines how social media are affecting journalism-e.g., studies of social media content that journalists produce, how journalists integrate social media into their work, social media as publishing platforms, and (to a lesser extent) news consumption on social media.

These areas of research have by now developed consistent themes based on the assumptions outlined here. Studies of social media and journalism frequently rely on two overarching narratives, one addressing normalization and one addressing control. Normalization focuses on changes in how journalists themselves relate to their profession and its institutional role, while control focuses on changes in journalists' relationships with their audiences and content. In both cases, the focus is on change, with the advent of digital communication-and specifically social media-being the fulcrum about which these changes have occurred. For instance, a greater adoption of social media is usually juxtaposed with a diminishing emphasis on "traditional" journalistic practices or roles.

The narrative of normalization suggests that journalists using social media have in some cases imposed existing journalistic norms on the new platforms and in others adopted elements of social media as newly journalistic [46]. This has been called a "hybrid normalization" [8] as new platforms become more deeply integrated into journalistic routines. The focus, then, is to learn which things change and which do not as social media platforms mesh with journalism. Thus far, it appears that journalists still prefer to separate themselves from their audiences [57] but are willing to offer more opinion and personality [3] [56]. The new normal on social media is also characterized by the hybrid mixing of contexts and practices as boundaries collapse between personal and professional, public and private [39]. In sum, longstanding journalistic conventions are being reconfigured on social media networks [40]. 
The narrative of control explores who is in charge of news selection, construction, and distribution. With respect to news audiences, researchers have treated social media as a boon, one resulting in more access, more personalization, more interactivity, and the possibility to embed news and conversations about it in social networks [41]. This increase in the audience's power comes in part as journalists' gatekeeping and agenda-setting influences wane [72]. When news is created and distributed outside the institutional logic of journalism [39], tensions arise between journalists' desire for professional control and audiences' abilities to circumvent it [47]. These tensions are exemplified by the question of who is a journalist and what qualifies as journalism in a world where the boundaries seem less fixed and more fluid [14]. In recent years, however, the question of control has become particularly pronounced in the context of publishing and distribution [2]: Once news is made by journalists, who controls how it moves and where it appears across various platforms (legacy and new, proprietary and nonproprietary, etc.) as well as how it is monetized accordingly? As digital intermediaries, especially Google and Facebook, control the primary distribution channels as well as an ever-larger share of digital advertising revenues, they exert wider control over the public visibility and economic viability of news. This is much to the confusion and consternation of news media organizations that simultaneously fear missing out on the massive audiences offered by such platforms but also worry about the longterm trade-offs of allowing technology companies to supersede them as publishers [62][7]. In all, social media has been understood as a conduit by which audiences and social media firms themselves have siphoned off some of journalists' power and control over news production and distribution by shifting these processes to platforms that news organizations don't own.

Against this backdrop of a decade of research on social media in journalism studies, we ask: What has not been accounted for adequately? This essay identifies three assumptions embedded in this line of research that need further questioning. At times, journalists, policymakers, and pundits also make assertions based on these assumptions, but we are concerned here with identifying what these assumptions mean for journalism studies particularly. As researchers seek to track and explain key developments in this area, what scents, as it were, have been lost amid the prevailing winds? There may be other assumptions embedded in the literature that merit scrutiny; these, however, appear to be the most salient and also the most likely to inhibit a more realistic and reflexive agenda for the study of social media and journalism moving forward. Finally, as authors, we are not immune to critique in this process. Having published many studies in this area, including one of the most-cited works on journalists' use of Twitter [46], we are well aware that we have contributed to the some of the problems outlined below and thus, akin to Witschge and colleagues [87], are "dealing with the mess (we made)" as self-critically as possible.

\section{Assumption 1: Social media would be a net positive}

If the main narratives around social media in journalism studies focus on change, it is usually assumed that such change will be for the better. Researchers have suggested that social media would become a primary enabler of greater transparency [66][69], reciprocity [49], and openness in journalism [48]. Social media should allow journalism to achieve a wider reach [41] and greater immediacy [89]. Some of this potential has been realized, but much of it has not. Social media has been a gold mine of source material [26], with some limited evidence that it may upend journalists' traditional reliance on official sources [42][65] - though the use of social media for sourcing tends to happen more in extraordinary events rather than in everyday reporting [6]. And, social media platforms play an indispensable role in circulating breaking news, particularly in crisis situations (e.g., [83]). But, on the other hand, the torrent of information is often so extreme that rather than attempt to verify content on social media, some journalists simply wait for other, larger news outlets to do so [12]. Social media provide the possibility of a new form of "live" journalism [89], and yet journalists live-tweeting the 2012 U.S. presidential debates spent less time fact-checking candidate claims and more time making jokes [22].

Beyond the problem of unrealized potential is the concern that major lines of research have all but baked in implicit optimism regarding social media. Researchers tend to assume, for example, that virtually all forms of journalist-audience interaction-by various approaches labeled engagement [58], participation [11], reciprocity [49], and more-are positive, in part because such interactions contribute to diminishing the much-maligned mask of objectivity, neutrality, and detachedness behind which journalistic work is black-boxed to public view (for a fuller discussion of notions such as "transparency is the new objectivity," see [84]). There are, of course, pro-social outcomes that may flow when audience members engage with journalists, such as the improvement in civility that emerges after journalists actively engage with the public in online comment sections [76]. But, based on our fieldwork, interviews, and observations, journalist-audience interactions may be overwhelmingly negative for journalists (let alone for users), and in ways not fully captured in the literature thus far.

Perhaps most salient among these problematic interactions are the many forms of harassment that are endemic to social media generally and increasingly a concern for journalists as well. Journalists on social media-particularly female and minority journalists, and particularly on Twitter - are frequently targeted by trolls and other malicious actors [74]. "They're smart, they're relentless, they'll find you," one Washington Post 
journalist told us about the trolls. ${ }^{2}$ While researchers have begun to study harassment and the forms it takes for journalists on social media [19], journalism studies has yet to reconcile what this means for the larger power dynamics on social media: who gets to speak, with what impact, and with what degree of accountability. For example, Robinson [70] suggests that power and privilege play a far greater part in negotiating roles among journalists, activists, and publics than previously acknowledged in journalism studies. And, what if, as increasingly appears to be the case, being on social media has predominantly meant putting oneself at the potential mercies of the "Twitter mob" [86] - a form of moral outrage that, while as old as the human species itself, has become accelerated in the age of social media [24]. Moreover, Massanari's [51] study of the \#Gamergate controversy, while not directly about journalism, points to two missed opportunities in journalism studies on social media: the relative neglect of Reddit as a social platform for study as well as the misogynistic subcultures that from Reddit spread to far parts of the social web. In all, in mostly focusing on the journalistic practices and audience interactions afforded by social media, journalism scholars have assumed positivity and thereby misread toxicity, particularly when it comes to gendered harassment.

The assumption that social media would be a net positive for journalism is also manifest in the industry logic that everyone should be there, which is felt keenly by journalists [45]. This normative "should" extends to research as well, especially when those studying technology adoption in newsrooms or other journalistic routines assume that those who do not use social media will be left out or left behind. The danger in this, of course, is that social media amplify journalism's pack mentality [25] in both scope and force, a fact sometimes overlooked in journalism studies. Journalists are regularly accused of piling on (focusing too much on one thing) or being thoroughly distracted (focusing on the wrong thing). The case is particularly acute when the president of the United States, already a subject of intense journalistic attention, has a habit of making provocative and controversial statements on Twitter. The upshot is that journalists now consider social media spats to be urgent, breaking news prompting them, for example, to send push notifications to smartphone users informing them that Donald Trump and his former FBI director are calling each other names. This pack mentality on social media remains understudied by journalism scholars, as does a related problem: the journalist's relationship to the so-called "filter bubble." Seeing only part of the world because you are ensconced in an echo chamber was initially a point of concern regarding citizens in going online [78]. But following a flurry of studies on the phenomenon of fake news after the 2016 U.S. presidential election (among them, [1]), it appears likely that echo chambers are more evident among journalists themselves, rather than ordinary users of social media. Audiences are actually exposed to a wider range of opinions and sources than might be expected [31], while journalists talk mainly to each other [57]. Moreover, network science research has found "a modest correlation between the ideologies of who a journalist follows on Twitter and the content he or she produces" [88]-a connection that has yet to be explored in journalism studies.

The industry logic that everyone must be on social media plays out at organizational and institutional levels as well. Our own fieldwork and interviews have shown that journalists are strongly encouraged or even forced to use social media, as supervisors begin to count how often journalists post and how widely these posts spread. Surprisingly, given the time involved in developing a social media brand, the return on this time investment is rarely questioned, either in the trade press or in the research literature. A notable exception is Chyi's work examining the value of online news, mobile news, and social media relative to other forms of news consumption and engagement (e.g., [43][20]); the findings often suggest that returns are well below the industry's hopes. Is it possible that audiences don't want or aren't impressed by journalists' online engagement (cf. [58])? Or, even in the best case, where journalists use social media to the full potential that scholars attribute to it, is it possible that the benefits to journalism are small relative to other investments of effort? Or simply that the power of social media platforms and their control over data collection and revenue generation make it unlikely, if not impossible, to build a business model under such conditions [7]? Overall, journalism studies has not sufficiently accounted for the time displacement of journalistic labor caused by a focus on social media. For example, it's worth considering: what are journalists not doing because they are managing social media? Such a question may be purely hypothetical, but it bears asking when assumptions of positive results from social media can lead researchers away from evaluating the tradeoffs of time, talent, and attention.

\section{Assumption 2: Social media reflects reality}

It is now common for journalists to point to social media posts, particularly tweets, as an indicator of what people are saying [4][13][30]. The logic is that Twitter is a modern version of person-on-the-street interviews, or even a journalistic stand-in for actual polling. While this was never a reliable way of gauging public opinion, the fact that Twitter makes these vox populi searchable and embeddable vastly reduces the effort that it takes to collect and call upon them. Its use has proliferated to the point that journalists see Twitter as a reliable source of news [53]. Indeed, as the Columbia Journalism Review acknowledged, in reporting on many news organizations erroneously embedding tweets from the infamous Internet Research Agency in

\footnotetext{
2 Personal communication, 28 February 2018.
} 
Russia, "American media outlets have a Twitter problem. The problem is not journalists' notorious addiction to the platform - it's their use of tweets as a way to include opinions from 'ordinary people.' Often, these ordinary people turn out not to be 'ordinary' or 'people' at all" [81]

In a similar vein, researchers have too often assumed that social media networks are a reasonable approximation of public opinion or other aspects of the (offline) social world. Most commonly, perhaps, this manifests itself in the use of social media to represent public sentiment in agendasetting studies (e.g., [73][59], even while many such studies readily acknowledge that they may not be accurate representations of the public. More broadly, several studies have attempted to use social media chatter as a predictor of election results (for a review, see [34]), and, in general, scholars have turned to social media posts and related trace data as evidence of what people are thinking or feeling. The problem, as [37] shows, is that bigger data is not necessarily better data: because people do not choose to use particular social media platforms at random, samples drawn from such spaces are inherently limited in their generalizability.

As such, Twitter, the most popular platform for U.S. journalists and the most popular for studies of journalism on social media, is demonstrably not representative of the public [54][44]. It's more appropriate to think of Twitter as $a$ public, rather than the public. While that concern is by now well understood, the broader composition and representation of social media publics is more complicated still, and has eluded many researchers examining social media and journalism. For example, some studies suggest that power dynamics and hegemony at work on social media shape which voices are present and which are heard (e.g., [62]). Media and other elites, in particular, have greater power and reach than the average social media user-even in cases, such as Andy Carvin's use of Twitter during the 2011 Arab Spring, when journalists presumably might be sourcing more non-elite opinion than usual [42]. In fact, it is common for social media metrics to quantify one's "influence," and in some cases this authority is institutionalized and made visible through a "verified" status (as in the blue checkmark on Twitter). In all, a more direct reckoning with the sharp differences that can exist among users has often been overlooked in this line of research. While some have attempted to separate groups in analysis of Twitter content [52], it is far more common to see social media publics treated as homogeneous wholes. To develop such broad characterizations obscures the power differentials that shape both who speaks and, more importantly, who is heard on social media (for further discussion, see [70]). It also may disregard subcultures and minority groupings such as Black Twitter [71]; these subnetworks are embedded within larger social media publics but may have unique characteristics and behaviors of their own [21]. This is to say nothing of those groups that are not online and thus simply are left out of any analysis of social media content.
The larger question is whether social media content, in any of its forms, is in fact an accurate representation of reality as it is lived and experienced by those creating the content. As journalists draw on evermore user content to gauge public sentiment and to tell stories about events at home and abroad, they are being trained to follow elaborate procedures for checking and verifying social media content as factual in a news context [6]. But it may be worth researchers' effort to consider whether social media content, even most of the time, is posted in good faith [38]. Efforts to manipulate public opinion in recent elections are an obvious example of this concern [1], but it appears at least possible that many social media users are motivated not by a desire to accurately express themselves or their observations but to perform an identity as a way of belonging [15]. These performances, as all front-stage social performances [36], are curated and crafted to achieve a particular end. This is particularly evident among social media "influencers" who go to great lengths to make their vlogs, Instagram photos, and selfies appear as natural and therefore "authentic" as possible, thereby influencing both the narrative that journalists convey about how "ordinary" people might get lucky and strike it rich as a YouTuber, while also masking the actual labor, precarity, and alwayson performativity behind the scenes [28]. It might also be that people simply act differently when online than they do in other social settings, emboldened by an "online disinhibition effect" [77]. Altogether, what people think and feel, and what they post on social media, may be two different things. Researchers should not only acknowledge these limitations but avoid research designs that treat social media content as a reflection of reality.

\section{Assumption 3: Social media matters over and above other factors}

The assumptions outlined so far suggest that, in the broad literature on journalism and social media during the past decade, there has been a two-part implicit expectation in many studies. First, that social media would be a net positive for journalism as an institution, for journalists as individuals, and for closer interactions with community members. And, second, that social media activities reflect something meaningful about the social world - that while Twitter publics and the like are by no means pure proxies for the populace, they are reasonable approximations that are therefore worth taking seriously. As we have noted already, both of those assumptions could be true in certain cases or under certain circumstances, and they are implicit in our own work. However, if we step back to question the surety of such assumptions, we are led to wonder: Has the journalism studies field paid too much attention to social media? And if so, what forces and factors in journalism's digital transformation have been neglected as a result?

Thus, the third and final assumption to untangle here is the assumption that, for the study of journalism, the phenomenon of social media matters in a singular way, 
over and above other factors. On one level, as with other forms of technologically oriented work in contemporary journalism, of course social media platforms, practices, and personnel matter. The decade-long dedication of resources, to a greater and greater degree, by journalists, their employers, and people at large virtually requires that journalism scholars pay attention to such developments. And indeed they have, as Figure 1 attests and as reviews such as Hermida's [39][40] chronicle in great detail. On another level, however, that journalism studies as a field has been consumed with studying how journalists tweet, like, and share implies a certain determinism in this arrangement: that social media has made an impact on journalistic perceptions and practices that matters over and above other types of influence that might otherwise have been chronicled if scholars had turned their gaze in another direction. Or, perhaps with greater consequence, we as researchers have attributed to social media credit and blame that rightly belongs elsewhere, amid the many seachanges washing over journalism in recent years.

Consider first the extent to which journalism studies has been preoccupied with social media and its associated dimensions. As Steensen and Ahva ([75], p. 1) note in their meta-analysis of the field, the latest movement in research on digital journalism has been focused on the "news ecosystem," the "news landscape," and "ambient" and "networked" forms of journalism - "all of which," they argue, "have emerged because of practices predominantly related to social media." The result, Steensen and Ahva [75] suggest, has been a widespread examination of the theories by which scholars make sense of journalism. While no doubt positive for the conceptual development of journalism as an area of study, this emphasis on practices afforded by fluid social media spaces perhaps has led researchers to overlook some pressing issues that span academic, industry, and policy concerns. For example, taking the 2017 Future of Journalism conference as an informal proxy for what journalism studies is actually studying today (and what it's not), [60] shows how studies of business models, innovation, and entrepreneurship are conspicuously absent. Moreover, while there is great emphasis on media practices amid social media, including emerging patterns of disinformation, he finds far less focus on the power of platform companies and their structural transformation of the information environment as a whole (see [7][61]. Thus, time spent analyzing tweets could be coming at the expense of analyzing the logics of algorithms, the political economy of technology giants, and other organizational and institutional arrangements that are reshaping the contexts for news subsidy (some recent examples include [35][82]. The powers we observe in social media platforms may in fact be wielded by their makers, markets, or even cultural shifts that are masked by a preoccupation with social media.

Furthermore, the field's focus on social media, its micro-practices and journalist-audience interactions, assumes that such things matter because they reflect earnest engagement between journalism and its publics in a deeply normative sense. As [38] deftly show, however, researchers may have been deceived in assuming an "earnest Internet." By this, they mean that "communication scholarship generally posits that people act rationally and in good faith; care about facts, truth, and authenticity; pursue ends in line with their political and social values and aspirations; and, more philosophically, are fundamentally good" (p. 1057). But then the 2016 U.S. election happened. Not only did it reveal a social media ecosystem coursing with racism, misogyny, and other ugliness, but it also revealed, they argue, that such expressions were often voiced "for the lulz" - not out of sincere political interest, but rather a more ambiguous aim of provoking for its own sake. Building on Phillips and Milner's [67] book The Ambivalent Internet, [38] argue that, in contemporary digital culture, "we cannot be certain of anyone's intent or motivations, meaning is indeterminate, accountability is nearly impossible, and the social and antisocial are intertwined" (p. 1058). Thus, it is ambivalence, not earnestness, that may be the orienting ethos of platforms increasingly marked by mischief, oddities, and antagonism. The upshot, they suggest, is a corrosive undermining of social trust, not merely on social media. "This goes far beyond the loss of trust in journalism or even institutions; it cuts to the heart of everyday social relations and public discourse" (p. 1058). If true, this re-evaluation calls into question the scores of studies on journalism and social media that carry an underlying assumption that social media matters - and matters quite a lot-because it represents an earnest extension of the public sphere.

\section{Conclusion}

To be clear, we are not suggesting that a decade of journalism studies research on social media has been for naught. Social media, by virtue of its vast diffusion, clearly matters for social life at large and for news in particular. In this essay, however, we are questioning the assumptions and associated blind spots that have developed in this research, and thus we argue that scholars-ourselves included-can be more critically reflexive in making sense of social media's impact for journalism as an institution, for journalists as individual media workers; for users, audiences, and communities engaged in news; and for the character of public discourse. In journalism studies especially but in the wider study of mediated conversations and communication research as well, scholars have too easily assumed that social media would be a net positive, reflects reality, and ultimately matters over and above other factors. These issues are exacerbated when journalism studies fails to connect itself to and build upon the work of adjacent fields also grappling with similar questions, including especially political communication research.

These assumptions, even while implicit, may be clouding our collective judgment and obscuring issues that otherwise call out for our attention. Indeed, in emphasizing the assumedly pro-social audience engagement or in 
fixating on the micro-practices of journalists' use of platforms, scholars too often have overlooked the gendered toxicity, the intra-journalistic insularity, and the overwhelming power of platform companies, among other concerns. Thus, in prioritizing social media activities above other factors, scholars arguably have given less attention to a number of critical issues that may be more consequential for the future of journalism - from matters of organizational innovation and business models to broader questions about how institutions and ideologies are constructing the internet architecture on which public conversations take place.

Ultimately, the explosive growth in research on social media and journalism can be linked with the similarly remarkable growth of journalism studies, a field of inquiry that is less than 20 years old as an institutionalized entity and is only now beginning to exhibit particular scholarly commitments [16]. Both are young and maturing areas of research, and are evolving in tandem with social, political, economic, and (especially) technological dynamics that can vary widely around the world. And, just as journalism studies has been dominated by perspectives from the Global North, the study of social media and journalism likewise has been limited not only by the underlying assumptions we have articulated here, but also by case studies that too often fail to include adequate diversity on matters of geography, culture, and language as well as race, class, and gender. As scholars extend their view to new contexts and conditions, they may well find additional ways of challenging the taken-for-granted assumptions of social media research.

\section{References}

[1] Allcott, H., \& Gentzkow, M. (2017). Social Media and Fake News in the 2016 Election. The Journal of Economic Perspectives: A Journal of the American Economic Association, 31(2), 211-236.

[2] Ananny, M. (2014). Networked Press Freedom and Social Media: Tracing Historical and Contemporary Forces in PressPublic Relations. Journal of Computer-Mediated Communication, 19(4), 938-956.

[3] Bane, K. C. (2017). Tweeting the agenda: How print and alternative web-only news organizations use Twitter as a source. Journalism Practice, 1-15.

[4] Beckers, K., \& Harder, R. A. (2016). “Twitter Just Exploded.” Digital Journalism, 4(7), 910-920.

[5] Beckett, C. (2011). SuperMedia: Saving journalism so it can save the world. Hoboken, NJ: John Wiley \& Sons.

[6] Belair-Gagnon, V. (2015). Social Media at BBC News: The Re-Making of Crisis Reporting. Routledge.

[7] Bell, E., \& Owen, T. (2017). The Platform Press: How Silicon Valley Reengineered Journalism. New York: Tow Center for Digital Journalism, Columbia University.
[8] Bentivegna, S., \& Marchetti, R. (2018). Journalists at a crossroads: Are traditional norms and practices challenged by Twitter? Journalism, 19(2), 270-290.

[9] Boczkowski, P. J., \& Papacharissi, Z. (Eds.). (2018). Trump and the Media. Cambridge, MA: MIT Press.

[10] Borger, M., van Hoof, A., Costera Meijer, I., \& Sanders, J. (2013). Constructing participatory journalism as a scholarly object: A genealogical analysis. Digital Journalism, 1(1), 117134.

[11] boyd, d. m., \& Ellison, N. B. (2007). Social Network Sites: Definition, History, and Scholarship. Journal of ComputerMediated Communication, 13(1), 210-230. https://doi.org/10.1111/j.1083-6101.2007.00393.x

[12] Brandtzaeg, P. B., Lüders, M., Spangenberg, J., RathWiggins, L., \& Følstad, A. (2016). Emerging Journalistic Verification Practices Concerning Social Media. Journalism Practice, 10(3), 323-342.

[13] Broersma, M., \& Graham, T. (2012). Social media as beat: Tweets as a news source during the 2010 British and Dutch elections. Journalism Practice, 6(3), 403-419.

[14] Carlson, M., \& Lewis, S. C. (Eds.). (2015). Boundaries of Journalism: Professionalism, Practices and Participation. New York: Routledge.

[15] Carlson, M., \& Lewis, S. C. (2018). News and the Networked Self: Performativity, Platforms, and Journalistic Epistemologies. In Z. Papacharissi (Ed.), A Networked Self and Platforms, Stories, Connections (pp. 29-42). New York, NY: Routledge.

[16] Carlson, M., Robinson, S., Lewis, S. C., \& Berkowitz, D. A. (2018). Journalism Studies and its Core Commitments: The Making of a Communication Field. The Journal of Communication, 68(1), 6-25.

[17] Carlsson, U., \& Pöyhtäri, R. (Eds.). (2017). The Assault on Journalism: Building Knowledge to Protect Freedom of Expression. Gothenburg, Sweden: Nordicom.

[18] Carr, C. T., \& Hayes, R. A. (2015). Social Media: Defining, Developing, and Divining. Atlantic Journal of Communication, 23(1), 46-65.

[19] Chen, G. M., Pain, P., Chen, V. Y., Mekelburg, M., Springer, N., \& Troger, F. (2018). "You really have to have a thick skin": A cross-cultural perspective on how online harassment influences female journalists. Journalism.

[20] Chyi, H. I., \& Chadha, M. (2012). News on new devices: Is multi-platform news consumption a reality? Journalism Practice, 6(4), 431-449.

[21] Clark, M. D. (2014). To tweet our own cause: A mixedmethods study of the online phenomenon "Black Twitter". Ph.D. Dissertation, University of North Carolina.

[22] Coddington, M., Molyneux, L., \& Lawrence, R. G. (2014). "Fact Checking the Campaign: How Political Reporters Use Twitter to Set the Record Straight (or Not)." The International Journal of Press/Politics, 19(4): 391-409.

[23] Creech, B., \& Mendelson, A. L. (2015). Imagining the 
journalist of the future: Technological visions of journalism education and newswork. The Communication Review, 18(2), 142-165.

[24] Crockett, M. J. (2017). Moral outrage in the digital age. Nature Human Behaviour, 1(11), 769-771.

[25] Crouse, T. (1973). The Boys on the Bus. New York: Random House.

[26] Diakopoulos, N., De Choudhury, M., \& Naaman, M. (2012). Finding and Assessing Social Media Information Sources in the Context of Journalism. In Proceedings of the SIGCHI Conference on Human Factors in Computing Systems (pp. 2451-2460). New York, NY, USA: ACM.

[27] Dubois, E., \& Blank, G. (2018). The echo chamber is overstated: the moderating effect of political interest and diverse media. Information, Communication and Society, 21(5), 729-745.

[28] Duffy, B. E., \& Wissinger, E. (2017). Mythologies of Creative Work in the Social Media Age: Fun, Free, and "Just Being Me." International Journal of Communication Systems, $11(0), 20$

[29] Edmonds, R., Guskin, E., Rosenstiel, T., \& Mitchell, A. (2012). Newspapers: Building digital revenues proves painfully slow. Retrieved from http://stateofthemedia.org/2012/newspapers-building-digitalrevenues-proves-painfully-slow $/$

[30] Farhi, P. (2009). "The Twitter Explosion." American Journalism Review 31: 26-31.

[31] Fletcher, R., \& Nielsen, R. K. (2018). Are people incidentally exposed to news on social media? A comparative analysis. New Media \& Society, 20(7), 2450-2468.

[32] Frish, Y., \& Greenbaum, D. (2017). Is social media a cesspool of misinformation? Clearing a path for patient-friendly safe spaces online. The American Journal of Bioethics: AJOB, 17(3), 19-21.

[33] Fuchs, C. (2017). Social Media: A Critical Introduction (Vol. 2nd). Thousand Oaks, CA: SAGE.

[34] Gayo-Avello, D. (2013). "A Meta-Analysis of State-of-theArt Electoral Prediction From Twitter Data." Social Science Computer Review 31(6), 649-79.

[35] Gillespie, T. (2018). Custodians of the Internet: Platforms, Content Moderation, and the Hidden Decisions That Shape Social Media. New Haven, CT: Yale University Press.

[36] Goffman, E. (1959). The Presentation of Self in Everyday Life. New York: Doubleday.

[37] Hargittai, E. (2015). Is bigger always better? Potential biases of big data derived from social network sites. The Annals of the American Academy of Political and Social Science, 659(1), 6376.

[38] Hedrick, A., Karpf, D., \& Kreiss, D. (2018). The Earnest Internet vs. the Ambivalent Internet. International Journal of Communication, 12(8), 1057-1064.

[39] Hermida, A. (2016). Social media and the news. In T. Witschge, C.W. Anderson, D. Domingo, \& A. Hermida (Eds.),
The SAGE Handbook of Digital Journalism (pp. 81-94). London: SAGE.

[40] Hermida, A. (2017). Twitter, breaking the news and hybridity in journalism. In B. Franklin \& S.A. Eldridge (Eds.), The Routledge Companion to Digital Journalism Studies (407-416). New York: Routledge.

[41] Hermida, A., Fletcher, F., Korell, D., \& Logan, D. (2012). Share, like, recommend: Decoding the social media news consumer. Journalism Studies, 13(5-6), 815-824.

[42] Hermida, A., Lewis, S. C., \& Zamith, R. (2014). Sourcing the Arab Spring: A Case Study of Andy Carvin's sources on Twitter during the Tunisian and Egyptian revolutions. Journal of Computer-Mediated Communication: JCMC, 19(3), 479-499.

[43] Ju, A., Jeong, S. H., \& Chyi, H. I. (2014). Will social media save newspapers? Journalism Practice, 8(1), 1-17.

[44] Jungherr, A., Schoen, H., Posegga, O., \& Jürgens, P. (2016). Digital trace data in the study of public opinion: An indicator of attention toward politics rather than political support. Social Science Computer Review, 35(3), 336-356.

[45] Lawrence, R G. (2015). "Campaign News in the Time of Twitter." In V. A. Farrar-Myers \& J. S. Vaughn (Eds.), Controlling the Message: New Media in American Political Campaigns (93-112). New York: NYU Press.

[46] Lasorsa, D. L., Lewis, S. C., \& Holton, A. E. (2012). Normalizing Twitter: Journalism practice in an emerging communication space. Journalism Studies, 13(1), 19-36.

[47] Lewis, S. C. (2012). The tension between professional control and open participation: Journalism and its boundaries. Information, Communication and Society, 15(6), 836-866.

[48] Lewis, S. C., \& Usher, N. (2013). Open source and journalism: Toward new frameworks for imagining news innovation. Media Culture \& Society, 35(5), 602-619.

[49] Lewis, S. C., Holton, A. E., \& Coddington, M. (2014). Reciprocal Journalism: A concept of mutual exchange between journalists and audiences. Journalism Practice, 8(2), 229-241.

[50] Marwick, A., \& Lewis, R. (2017). Media manipulation and disinformation online. New York: Data \& Society Research Institute.

[51] Massanari, A. (2015). \#Gamergate and The Fappening: How Reddit's algorithm, governance, and culture support toxic technocultures. New Media \& Society, 19(3), 329-346.

[52] McGregor, S. C., Mourão, R. R., \& Molyneux, L. (2017). Twitter as a tool for and object of political and electoral activity: Considering electoral context and variance among actors. Journal of Information Technology \& Politics, 14(2), 154-167.

[53] McGregor, S., \& Molyneux, L. (2016). Twitter's influence on news judgment: An experiment among journalists. Paper presented at the annual meeting of AEJMC, Minneapolis.

[54] Mitchell, A, \& Hitlin, P. (2013). "Twitter Reaction to Events Often at Odds with Overall Public Opinion." Pew Research Center. http://www.pewresearch.org/2013/03/04/twitter-reactionto-events-often-at-odds-with-overall-public-opinion/ 
[55] Mitchell, A., Rosenstiel, T., \& Christian, L. (2012). "What Facebook and Twitter Mean for News." In The State of the News Media 2012. http://stateofthemedia.org/2012/mobile-devicesand-news-consumption-some-good-signs-for-journalism/whatfacebook-and- twitter-mean-for-news/

[56] Molyneux, L. \& Holton, A.E. (2015). Branding (health) journalism: Perceptions, practices, and emerging norms. Digital Journalism, 3(2), 225-242

[57] Molyneux, L., \& Mourão, R. R. (2017). "Political journalists' normalization of Twitter: Interaction and new affordances." Journalism Studies.

[58] Nelson, J. L. (2018). The elusive engagement metric. Digital Journalism, 6(4), 528-544.

[59] Neuman, R. W., Guggenheim, L., Mo Jang, S., \& Bae, S. Y. (2014). The dynamics of public attention: Agenda-setting theory meets big data. The Journal of Communication, 64(2), 193-214.

[60] Nielsen, R. K. (2017, September 14). What is journalism studies studying? Retrieved May 1, 2018, from https://rasmuskleisnielsen.net/2017/09/14/what-is-journalismstudies-studying/

[61] Nielsen, R. K., \& Ganter, S. A. (2017). Dealing with digital intermediaries: A case study of the relations between publishers and platforms. New Media \& Society, 1461444817701318.

[62] Parmelee, J. H. (2013). "Political Journalists and Twitter: Influences on Norms and Practices." Journal of Media Practice, 14(4): 291-305.

[63] Parr, B. (2009, May 26). The New York Times hires a social media editor; does it need one? Mashable. Retrieved from http://mashable.com/2009/05/26/nyt-social-media-editor/.

[64] Patel, S. (2018). 'A fun adventure, not a business': The Weather Channel stopped publishing video on Facebook. Digiday. Retrieved from https://digiday.com/media/the-weatherchannel-has-walked-away-from-facebook-video/

[65] Paulussen, S., \& Harder, R. A. (2014). Social media references in newspapers. Journalism Practice, 8(5), 542-551.

[66] Phillips, A. (2010). Transparency and the new ethics of journalism. Journalism Practice, 4(3): 373-82.

[67] Phillips, W., \& Milner, R. M. (2018). The Ambivalent Internet: Mischief, Oddity, and Antagonism Online. Somerset, NJ: John Wiley \& Sons.

[68] Quandt, T. (2018). Dark participation. Media and Communication.

[69] Revers, M. (2014). The Twitterization of news making: Transparency and journalistic professionalism. The Journal of Communication, 64(5), 806-826.

[70] Robinson, S. (2017). Networked News, Racial Divides: How Power and Privilege Shape Public Discourse in Progressive Communities. Cambridge, UK: Cambridge University Press.

[71] Richardson, A. V. (2017). Bearing Witness While Black. Digital Journalism, 5(6), 673-698.

[72] Singer, J. B. (2014). User-generated visibility: Secondary gatekeeping in a shared media space. New Media \& Society, 16(1), 55-73.

[73] Skogerbø, E., \& Krumsvik, A. H. (2015). Newspapers,
Facebook and Twitter. Journalism Practice, 9(3), 350-66.

[74] Spike, C., \& Vernon, P. (2017, July 28). "It was super graphic": Reporters reveal stories of online harassment. Columbia Journalism Review. Retrieved from https://www.cjr.org/covering_trump/journalists-harassmenttrump.php

[75] Steensen, S., \& Ahva, L. (2015). Theories of Journalism in a Digital Age: An exploration and introduction. Journalism Practice, 9(1), 1-18.

[76] Stroud, N. J., Scacco, J. M., Muddiman, A., \& Curry, A. L. (2015). Changing Deliberative Norms on News Organizations' Facebook Sites. Journal of Computer-Mediated Communication: JCMC, 2O(2), 188-203.

[77] Suler, J. (2004). The online disinhibition effect. Cyberpsychology \& Behavior, 7(3), 321-326.

[78] Sunstein, C. R. (2018). \#Republic: Divided Democracy in the Age of Social Media. Princeton: Princeton University Press.

[79] The Economist (2017, November 4). Do social media threaten democracy? Retrieved from https://www.economist.com/news/leaders/21730871-facebookgoogle-and-twitter-were-supposed-save-politics-goodinformation-drove-out

[80] Tufekci, Z. (2017). Twitter and Tear Gas: The Power and Fragility of Networked Protest. New Haven, CT: Yale University Press.

[81] Tworek, H. (2018, March 27). Tweets are the new vox populi. Columbia Journalism Review. Retrieved from https://www .cjr.org/analysis/tweets-media.php

[82] Vaidhyanathan, S. (2018). Antisocial Media: How Facebook Disconnects Us and Undermines Democracy. Oxford University Press.

[83] Vis, F. (2013). Twitter as a reporting tool for breaking news. Digital Journalism, 1(1), 27-47.

[84] Vos, T. P., \& Craft, S. (2017). The Discursive Construction of Journalistic Transparency. Journalism Studies, 18(12), 15051522 .

[85] Weaver, D. H., Willnat, L. (2016). Changes in U.S. journalism: How do journalists think about social media? Journalism Practice, 10(7), 844-55.

[86] Williamson, K. D. (2018, April 20). When the Twitter Mob Came for Me. WSJ Online. Retrieved from https://www.wsj.com/articles/when-the-twitter-mob-came-forme-1524234850

[87] Witschge, T., Anderson, C. W., Domingo, D., \& Hermida, A. (2018). Dealing with the mess (we made): Unraveling hybridity, normativity, and complexity in journalism studies. Journalism, 1464884918760669 .

[88] Wihbey, J., Coleman, T. D., Joseph, K., \& Lazer, D. (2017, August 22). Exploring the Ideological Nature of Journalists' Social Networks on Twitter and Associations with News Story Content. arXiv [cs.SI]. Retrieved from http://arxiv.org/abs/1708.06727

[89] Ytreberg, E. (2009). Extended liveness and eventfulness in multi-platform reality formats. New Media \& Society, 11(4), 467485. 